\title{
Optical Coherence Tomography Images of Epithelial Ingrowth and Flap Striae in Traumatic Complication of Laser-Assisted In Situ Keratomileusis Cornea
}

Kyong Jin $\mathrm{Cho}^{1}$

Phil-Sang Chung ${ }^{2}$

${ }^{1}$ Department of Ophthalmology, College of Medicine, Dankook University, Cheonan, Korea ${ }^{2}$ Department of Otolaryngology-Head and Neck Surgery, College of Medicine, Dankook University, Cheonan, Korea

Received May 30, 2016

Revised June 12, 2016

Accepted June 12, 2016

\section{Correspondence}

Phil-Sang Chung

Department of Otolaryngology-Head and Neck Surgery, College of Medicine, Dankook University, 119, Dandae-ro, Dongnam-gu, Cheonan 31116 , Korea

Tel: +82-41-550-3975

Fax: +82-41-559-7940

E-mail: pschung@dankook.ac.kr

(C) Korean Society for Laser Medicine and Surgery

(c) This is an open access article distributed under the terms of the Creative Commons Attribution NonCommercial License (http://creativecommons.org/ licenses/by-nc/4.0) which permits unrestricted noncommercial use, distribution, and reproduction in any medium, provided the original work is properly cited.
Laser-assisted in situ keratomileusis (LASIK) surgery is one of the most commonly performed operations in the world. However, there are postoperative complications associated with LASIK flaps. Traumatic dislocation of LASIK flaps may occur many years after the refractive surgery. Flap striae and epithelial ingrowth are usually associated with flap dislocation. We described an appearance of epithelium, haze, and striae in the flap interface as visualized by high-resolution anterior segment optical coherence tomography. This experience may provide appropriate knowledge to clinicians for differentiating between inflammation, haze, epithelium, and fluid in the interface, as well as provide aid in the management of post-LASIK complications.

\section{Key words}

Epithelial ingrowth; Flap striae; Laser-assisted in situ keratomileusis; Optical coherence tomography 


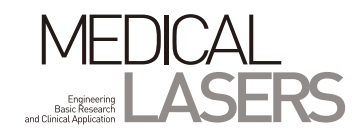

\section{INTRODUCTION}

Laser-assisted in situ keratomileusis (LASIK) surgery is among the most common operations in the world. It is estimated that over 15 million patients have undergone LASIK, and approximately $95 \%$ of these patients are satisfied after their operation. 'The LASIK flap allows for rapid visual recovery with minimal pain; however, LASIK flap-associated postoperative complications do occur. Traumatic dislocation of LASIK flaps can occur several years after refractive surgery. ${ }^{2}$ Epithelial ingrowth and flap striae are usually associated with flap dislocation by trauma. We describe cases of epithelial ingrowth and flap striae that is associated with traumatic complications of LASIK flap using optical coherence tomography (OCT) images. The complicated interface pathologies that included epithelium and fluid were delineated with a spectral domain OCT system (Carl Zeiss Inc., Zena, Germany).

\section{CASE REPORT}

Case 1. A 41-year-old woman visited with decreased visual acuity of right eye which started 10 months previously when she hit her left eye accidentally with a bough. The patient had undergone microkeratome LASIK surgery in both eyes ten years before. The vision was 20/20 in the right eye and $20 / 25$ in the left eye. On slit lamp examination there was epithelial ingrowth underneath the flap (Fig. 1A; white arrow). Anterior segment (AS) OCT of the patient's cornea showed the epithelial ingrowth underneath the flap (Fig. 1B; red arrow). One week later, the flap was surgically repositioned with removal of the ingrowing epithelium with No. 15 blade and 0.02\% mitomycin $\mathrm{C}$. Three months after the procedure, the flap was perfectly attached and positioned and the vision was 20/20 with a mild interface haze.

Case 2. A 57-year-old male, was referred to our hospital with impairment of vision which started two days previously when he had sustained a basketball injury to
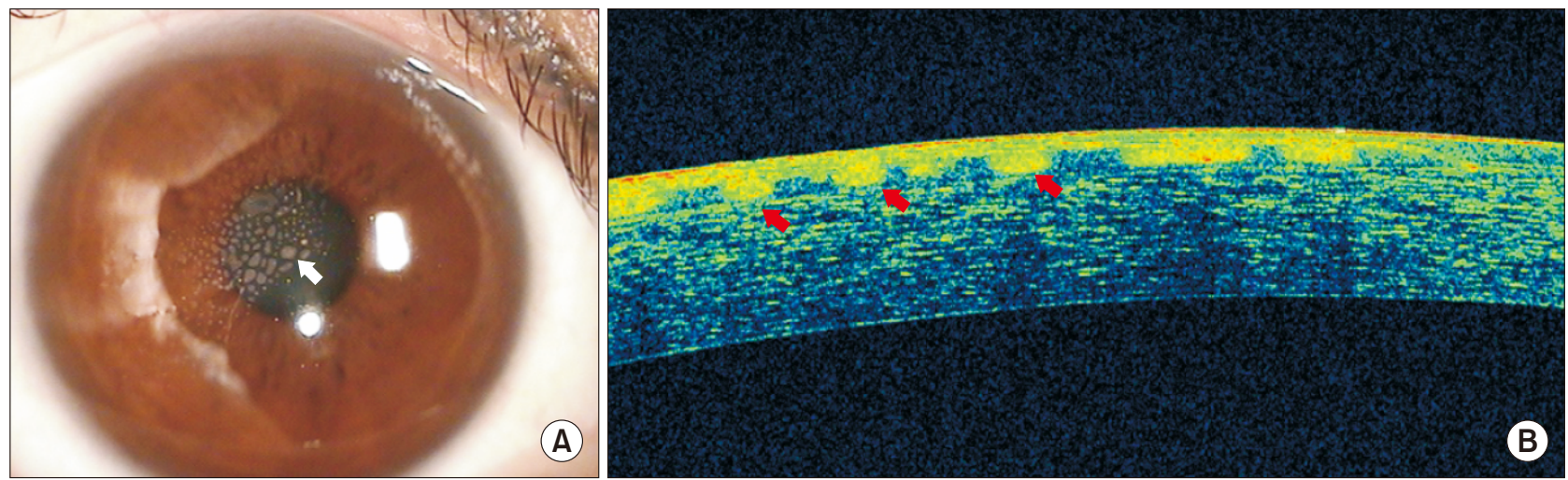

Fig. 1. Epithelial ingrowth, slit-lamp photo (A) and anterior segment optical coherence tomography (B) scan of epithelial ingrowth (arrows) after traumatic LASIK flap dislocation.
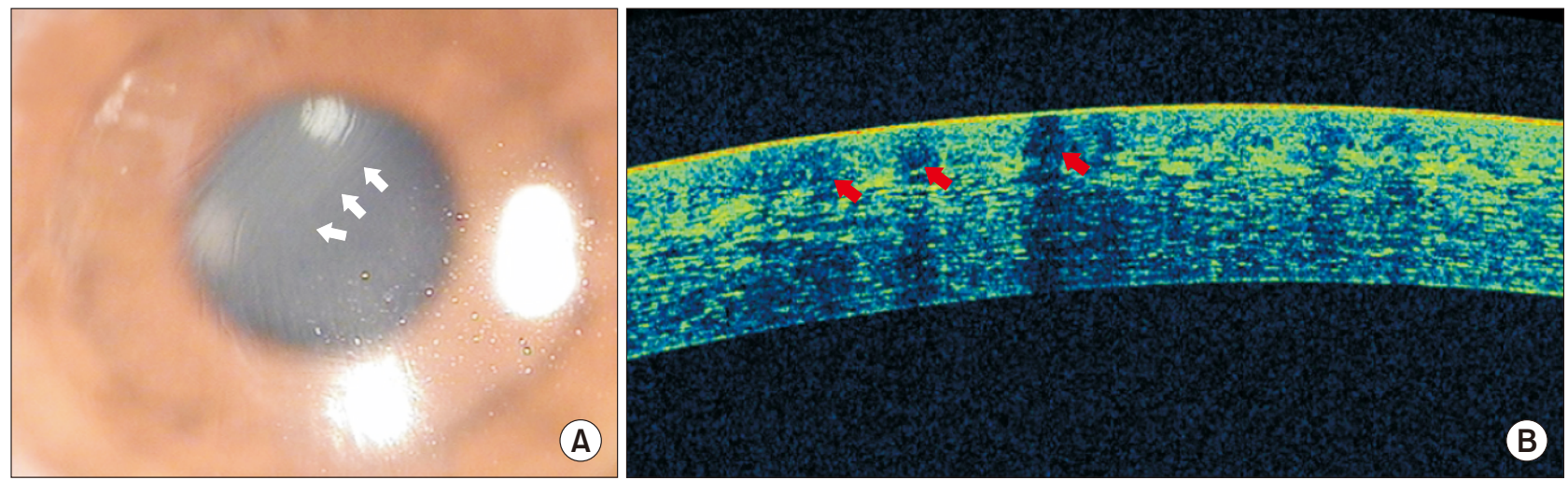

Fig. 2. Flap striae, slit-lamp photo (A) and anterior segment optical coherence tomography (B) scan of flap striae (arrows) after traumatic LASIK flap dislocation. 
the cornea of his left eye. The patient had undergone microkeratome LASIK surgery in both eyes 20 years before. The vision was 20/20 in the right eye and 20/50 in the left eye. On slit lamp examination there was a LASIK flap dislocation with wrinkling (Fig. 2A; white arrow). Anterior segment OCT of the patient's cornea showed the flap striae (Fig. 2B; red arrow). One week later, the flap was lifted and hydrated with distilled water and then stretched it back into position. Three months after the procedure, the flap was perfectly attached and positioned and the vision was $20 / 20$.

\section{DISCUSSION}

Although LASIK has become a popular technique for refractive surgery, there are a number of complications that can arise following such procedures, such as interface haze, flap edge scarring, epithelial ingrowth and flap striae or folds. ${ }^{3}$ One of the most common complications of LASIK is postoperative striae associated with the creation of the corneal flap, which have a variety of appearances. ${ }^{4}$ Epithelial ingrowth is the growth of corneal epithelial cells within the flap interface. Epithelial ingrowth is also a relatively common complication following LASIK, with reported incidence ranging between $0.2 \%$ and $12 \%$ after primary treatment and up to $32 \%$ in cases requiring retreatment. ${ }^{5,6}$ Clinically significant ingrowth with impaired vision or discomfort is much less common, however, with incidence at most around 3\%. ${ }^{7}$

Although often evident on clinical examination, OCT imaging can be useful in visualizing fine details and structural changes associated with flap displacement such as the extent of the epithelial ingrowth, and to confirm proper apposition of the flap edges after repositioning. ${ }^{8}$

In summary, we described the appearance of epithelium, haze, and striae in the flap interface as visualized by both high-resolution anterior segment OCT. This knowledge may help clinicians differentiate between inflammation, haze, epithelium, and fluid in the interface and aid in the management of post-LASIK complications.

\section{ACKNOWLEDGMENTS}

This research was supported by a grant of the Korea Health Technology R\&D Project through the Korea Health Industry Development Institute (KHIDI), funded by the Ministry of Health \& Welfare, Republic of Korea lgrant number: HI15C1524).

\section{REFERENCES}

1. Solomon KD, Fernández de Castro LE, Sandoval HP, Biber JM, Groat B, Neff KD, et al. LASIK world literature review: quality of life and patient satisfaction. Ophthalmology 2009;116:691-701.

2. Tumbocon JA, Paul R, Slomovic A, Rootman DS. Late traumatic displacement of laser in situ keratomileusis flaps. Cornea 2003; 22:66-9.

3. Naripthaphan $P$, Vongthongsri A. Evaluation of the reliability of the Nidek MK-2000 microkeratome for laser in situ keratomileusis. J Refract Surg 2001;17:S255-8.

4. Solomon KD, Holzer MP, Sandoval HP, Vargas LG, Werner L, Vroman DT. Refractive surgery survey 2001. J Cataract Refract Surg 2002;28:346-55.

5. Ayala MJ, Alió JL, Mulet ME, De La Hoz F. Treatment of laser in situ keratomileusis interface epithelial ingrowth with neodymium:yytrium-aluminum-garnet laser. Am J Ophthalmol 2008;145:630-4.

6. Lindfield D, Ansari G, Poole T. Nd:YAG laser treatment for epithelial ingrowth after laser refractive surgery. Ophthalmic Surg Lasers Imaging 2012;43:247-9.

7. Rojas MC, Lumba JD, Manche EE. Treatment of epithelial ingrowth after laser in situ keratomileusis with mechanical debridement and flap suturing. Arch Ophthalmol 2004;122:9971001.

8. Rosas Salaroli CH, Li Y, Huang D. High-resolution optical coherence tomography visualization of LASIK flap displacement. J Cataract Refract Surg 2009;35:1640-2. 